\title{
PERANAN HUKUM DESA ADAT BEGAWAN TERKAIT PENCEGAHAN ALIH FUNGSI LAHAN DI KAWASAN ALIRAN SUNGAI AYUNG
}

\author{
Oleh : \\ I Made Hendra Wijaya \\ Ida Ayu Agung Apsari, Kadek Krismayanti, I Wayan Nadi Sumanta, \\ Putu Gd. Bayu Suta Pratama \\ Fakultas Hukum Universitas Mahasaraswati Denpasar
}

\begin{abstract}
The importance of the existence of Begawan Adat Village located in Payangan Subdistrict of Bali Province in maintaining the Ayung River watershed which aims to prevent land conversion, so that the Ayung River Basin does not become damaged and disrupt the lives of the people and ecosystems in the area. In terms of protecting the Ayung watershed, the village of Adat Begawan needs customary law as an umbrella in legalizing the actions of the people of the Adat Begawan village in protecting the Ayung river basin. Customary law owned by the Begawan Adat village is in the form of Awig-awig, and Pararem, as well as some customs which are usually contained in the Dresta, where all the customary laws in the Begawan traditional village are based on the Tri Hita Karana concept in protecting the Ayung River Basin.
\end{abstract}

Keywords: Customary Law, Begawan Customary Village, Ayung River Flow

\begin{abstract}
Abstrak
Pentingnya keberadaan Desa Adat Begawan yang terletak di Kecamatan Payangan Propinsi Bali dalam menjaga kawasan aliran sungai Ayung yang bertujuan untuk mencegah alih fungsi lahan, agar kawasan aliran sungai Ayung tidak menjadi rusak dan mengganggu kehidupan masyarakat dan ekosistem yang ada di kawasan tersebut. Dalam hal melindungi kawasan aliran sungai Ayung, desa Adat Begawan memerlukan hukum adat sebagi payung dalam melegalkan tindakan masyarakat desa Adat Begawan dalam melindungi kawasan aliran sungai Ayung. Hukum adat yang dimiliki oleh desa Adat Begawan berupa Awig-awig, dan Pararem, serta beberapa kebiasaan yang bisanya terdapat dalam dresta desa adat Begawan, dimana semua hukum adat yang ada di Desa Begawan berlandaskan pada konsep Tri Hita Karana dalam menjaga kawasan aliran sungai Ayung.
\end{abstract}

Kata Kunci: Hukum Adat, Desa Adat Begawan, Aliran Sungai Ayung

\section{A. PENDAHULUAN}

1. Latar Belakang Masalah

Kabupaten Gianyar merupakan

salah satu dari 4 kecamatan yang

dilewati oleh aliran sungai Ayung yang merupakan sungai terpanjang di

Bali yang memiliki panjang 68,5 KM. Salah satu daerah yang mendapatkan aliran sungai Ayung di Kabupaten Gianyar adalah Desa 
Adat Begawan, Kecamatan

Kecamatan Payangan namun seperti

Payangan, Kabupaten Gianyar yang diketahui bahwa perkembangan memiliki potensi ekowisata yaitu berupa Kawasan Aliran Sungai Ayung yang sering digunakan untuk kegiatan wisata arung jeram (Rafting). Selain kegiatan wisata arung jeram (Rafting), di wilayah Desa Adat Begawan, Kecamatan Payangan juga terdapat hotel dan villa yang berdiri di kawasan tebing aliran sungai Ayung, seperti halnya COMO Shambhala Estate ${ }^{1}$, Ayung Resort Ubud², Rijasa Agung - Bali Ubud Luxury Hotel Resort Villa ${ }^{3}$, Villa Gana Begawan ${ }^{4}$.

Kegiatan di bidang pariwisata memang sangat menjanjikan di setiap daerah di Bali yang memang terkenal akan daya tariknya khususnya di Desa Adat Begawan,

\footnotetext{
1 Como Shambhala estate, 2019, Como Shambhala estate, https://www.comohotels.com/en/comosham bhalaestate, diakses pada 20 November 2019.
2 Ayung Resort Ubud, 2019, Ayung Ubud Resort https://www.ayungresortubud.com/en-gb, diakses pada 20 November 2019.

3 Rijasa Agung - Bali Ubud Luxury Hotel Resort Villa, 2019, Rijasa Agung Bali Ubud Luxury Hotel Resort Villa, ijasa.com, diakses pada 20 November 2019.

4 Hikersbay,Villa Gana Begawan, http://hikersbay.com/asia/indonesia/hotel/id/ villa-gana-begawan.html?lang=en, diakses pada 20 November 2019.
}

wisatawan perlu juga memikirkan kelestarian dari alam di sekitar kawasan wisata khusunya di kawasan Desa Adat Begawan, Kecamatan Payangan. Pembangunan yang dilakukan secara terus menerus tanpa memperhatikan potensi alam yang ada dapat memberikan dampak buruk baik untuk kehidupan saat ini maupun yang akan datang. Untuk itu sangat diperlukan upaya pencegahan terkait kegiatan alih fungsi lahan secara besar-besaran. Hai ini sangat penting untuk diperhatikan agar hal serupa tidak terjadi seperti di wilayah Kabupaten Tabanan, dimana berdasarkan data di Dinas Pertanian mencatat telah terjadi kegiatan alih fungsi lahan dari tahun ketahun yakni sebagai berikut, di tahun 2011 sebanyak 40 hektare, tahun 2012 sebanyak 47 hektare, tahun 2013 sebanyak 204 hektare, tahun 2014 sebanyak 222 hektare, tahun 2015 sebanyak 248 hektare, dan meningkat kembali di tahun 2016 sebanyak 262 hektare. Dimana ratarata alih fungsi lahan pertanian di Kabupaten Tabanan sebnayak 196,6 
hektare pertahunnya dengan rincian 129,80 hektare menjadi lahan perkebunan dan menjadi perumahan, perkantoran, hingga akomodasi

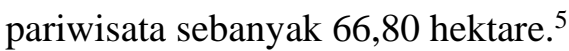

Pada tahun 2017 Dinas Lingkungan Hidup dan Kebersihan (LHK) Kabupaten Badung melakukan pendataan ke sejumlah akomodasi pariwisata di daerah aliran sungai ayung terkait dugaan adanya limbah yang mencemari sungai ayung yang diduga disebabkan terjadi pembuangan limbah cair oleh pelaku wisata di sekitar aliran sungai Ayung ${ }^{6}$, selain itu dikawasan aliran sungai Ayung sering terjadi longsor ${ }^{7}$. Maka dari itu, peran serta masyarakat Desa Adat Begawan, Kecamatan Payangan sangat penting untuk terus memperhatikan pelaksanaan

5 Radar Bali, 2018, Alih Fungsi Lahan Empat Kecamatan di Tabanan Masif, Ini Pemicunya, https://radarbali.jawapos.com/read/2018/04/ 16/65481/alih-fungsi-lahan-empatkecamatan-di-tabanan-masif-ini-pemicunya, diakses pada 21 November 2019.

6 Tribun Bali.com.2017, Sungai Ayung Badung Tercemar, eh longsor bikin petani tidak bisa menanam, https://bali.tribunnews.com/2017/03/04/sung ai-ayung-badung-tercemar-eh-longsor-bikinpetani-tak-bisa-menanam, diakses pada 21 November 2019.

${ }^{7}$ Ibid pembangunan yang ada agar dapat terhindar dari alih fungsi lahan yang disebabkan oleh keberadaan destinasi wisata khususnya di kawasan Aliran Sungai Ayung. Dalam hal ini keberadaan filosofis Tri Hita Karana yaitu tiga hubungan yang harmonis antara manusia dengan Tuhan, yang disebut dengan Parhyangan, hubungan antara manusia dengan manusia yang disebut dengan Pawongan, serta hubungan manusia dengan lingkungannya atau yang disebut dengan Palemahan dapat digunakan untuk melindungi kawasan Aliran Sungai Ayung dari kegiatan alih fungsi lahan yang disebabkan oleh kegiatan wisata. Begitu juga dengan keberadaan Hukum Adat berupa Awig-awig yang dimiliki oleh Desa Adat Begawan, Kecamatan Payangan juga sangat penting dan dapat diterapkan mengingat didalamnya terdapat bagaimana masyarakat adat menjaga hubungan yang harmonis seperti yang terdapat didalam filosofis Tri HIta Karana, serta berisikan sanksi dan kewajiban-kewajiban yang dapat diberikan kepada masyarakatnya sendiri atau pun pihak lainnya yang 
memiliki asset atau bertempat tinggal di wilayah Desa Adat Begawan, Kecamatan Payangan.

\section{B. PEMBAHASAN}

\section{Hukum Desa Adat Begawan Payangan}

Desa Adat Begawan merupakan salah satu desa adat yang masih ada keberadaannya di Bali khusunya di Kabupaten Gianyar. Di dalam Pasal 1 ayat (8) Peraturan Daerah Provinsi Bali Nomor 4 Tahun 2019 Tentang Desa Adat di Bali menyatakan bahwa Desa Adat adalah kesatuan masyarakat hukum adat di Bali yang memiliki wilayah, kedudukan, susunan asli, hak-hak tradisional, harta kekayaan sendiri, tradisi, tata krama pergaulan hidup masyarakat secara turun temurun dalam ikatan tempat suci (kahyangan tiga atau kahyangan desa), tugas dan kewenangan serta hak mengatur dan mengurus rumah tangganya sendiri. Lebih lanjut lagi unsur-unsur desa adat dilihat dari segi keilmiahan sebagai masyarakat hukum adat, maka unsur tersebut terdiri dari: ${ }^{8}$

$8 \mathrm{Ni}$ Made Lidia Lestari Karlina Dewi,2019 Peran Desa Pakraman Dalam
1. Menunjukkan bentuk suatu kesatuan wilayah.

2. Mewujudkan satu kesatuan kekerabatan berupa Krama Desa, dan terhimpun dalam banjar-banjar yang tidak terpisahkan dari kegiatan desa adat.

3. Memiliki kesatuan tempat pemujaan Khayangan Tiga.

4. Adanya ayahan ke desa (tugas dan kewajiban sebagai krama desa).

5. Memiliki struktur pemerintahan, Awig-awig dan Milik Desa (druwe desa).

Dalam hal mengatur dan mengurus rumah tangganya sendiri desa adat haruslah memiliki sebuah aturan, begitu pula Desa Adat Begawan memiliki aturan sendiri baik itu berupa Awig-awig ${ }^{9}$,

Pembentukan Pararem Terkait Penyelesaian Konflik Alih Fungsi Lahan (Studi Kasus Di Desa Pakraman Tunjuk, Kabupaten Tabanan), Jurnal Magister Hukum Udayana, Volume 5, Nomor 3, September 2016, pISSN: 2302-528X, h. 440.

9 Berdasarkan Pasal 1 ayat 29 Peraturan Daerah Provinsi Bali Nomor 4 Tahun 2019 tentang Desa Adat di Bali menyatakan awig-awig adalah aturan yang dibuat oleh Desa Adat dan/atau Banjar Adat yang berlaku bagi Krama Desa Adat, Krama Tamiu, dan Tamiu 
Pararem $^{10}$, maupun dalam bentuk Dresta $^{11}$. Berdasarkan pada Peraturan Daerah Provinsi Bali Nomor 4 Tahun 2019 Tentang Desa Adat di Bali, Desa Adat Begawan pun memiliki kewenangan dalam membuat aturan sendiri berupa Awig-awig, Pararem maupun Dresta yang mengatur masyarakat di wilayahnya sendiri, baik itu warga asli, warga pendatang, atau orang yang bertamu diwilayah Desa Adat Begawan.

Awig-awig memuat aturanaturan dasar yang menyangkut wilayah adat, krama desa adat, keagamaan serta sanksi. Awig-awig desa adat, merupakan hukum adat yang mempunyai fungsi untuk mengatur dan mengendalikan perilaku warga masyarakat dalam pergaulan hidupnya guna mencapai

10 Berdasarkan Pasal 1 ayat 30 Peraturan Daerah Provinsi Bali Nomor 4 Tahun 2019 tentang Desa Adat di Bali menyatakan Pararem adalah aturan/keputusan Paruman Desa Adat sebagai pelaksanaan Awig-Awig atau mengatur hal-hal baru dan/atau menyelesaikan perkara adat/wicara di Desa Adat.

11 Berdasarkan Pasal 1 ayat 31 Peraturan Daerah Provinsi Bali Nomor 4 Tahun 2019 tentang Desa Adat di Bali menytakan Dresta adalah adat kebiasaan/tradisi yang diwarisi secara turun temurun dan masih ditaati oleh Desa Adat. ketertiban dan ketentraman masyarakat. Arti penting Awig-awig adalah merupakan pengikat persatuan dan kesatuan krama desa guna menjamin kekompakan dan keutuhan dalam menyatukan tujuan bersama mewujudkan kehidupan yang aman, tertib, dan sejahtera diwilayah desa adat. ${ }^{12}$

Di dalam Awig-awig Desa Adat Begawan dilandasi pada local genius seperti halnya Tri Hita Karana, Bhuana Agung-Bhuana Alit, selain dilandasi oleh local genius, awig-awig Desa Adat Begawan juga dilandasi oleh tata cara Agama yaitu Agama Hindu di Bali dan Pancasila sebagai dasar filosofis dan ideologi Bangsa Indonesia dan UndangUndang Dasar Negara Kesatuan Republik Indonesia Tahun 1945.

Secara garis besar yang diatur dalam Awig-awig Desa Adat Begawan adalah Prathama Sarga, Dwitya Sargah Yang, Tritya Sargah, Cathurtas Sargah, Pancama Sargah, Sat Sargah, Saptama Sargah,dan Asthama Sargah. Terkait dengan Prathama Sarga didalamnya

$12 \mathrm{Ni}$ Made Lidia Lestari Karlina Dewi, Lok. Cit. 
mengatur Aran Lan Wawidangan Desa, untuk Dwitya Sargah yang didalamnya mengatur tentang Petitis Lan Pamikukuh, untuk Tritya Sargah mengenai Sukerta Tata Pakraman yang terdiri dari Indik Krama, Indik Prajuru/ Dulun Desa, Indik Kulkul, Indik Paruman, Indik Druwen Desa, dan Indik Sukerta Pamitegep yang terdiri mengatur mengenai Karang, Tegal lan Carik, Pepayonan, wewangunan, wewalungan, bhaya, Panyanggra Banjar. Cathurtas Sargah yang mengenai Sukerta Tata Agama yang terdiri dari hal yang mengenai Indik Dewa Yadnya, Indik Resi Yadnya, Indik Pitra Yadnya, Indik Manusa Yadnya, dan Bhuta Yadnya. Pancama Sargah yang mengatur mengenai Sukerta Tata Pawongan yang terdiri dari hal yang mengenai Indik Pawiwahan, Indik Nyapian, Indik Sentana, dan Indik Warisan. Sat Sargah yang mengatur mengenai Wicara Lan Pamidanda yang terdiri dari Indik Wicara dan Indik Pamidanda. Saptama Sargah yang mengatur mengenai NguwahNguwuhin Awig-awig, dan Astawa
Sargah yang mengatur mengenai Samapta.

\section{Peranan Hukum Desa Adat Begawan Dalam Pencegahan Alih Fungsi Lahan Oleh Adanya Kegiatan Pariwisata Di Daerah Kawasan Aliran Sungai Ayung}

Dalam Pasal 1 ayat (1) Undang-Undang Nomor 41 Tahun 2009 Tentang Perlindungan Lahan Pertanian dan Pangan Berkelanjutan disebutkan bahwa lahan adalah bagian daratan dari permukaan bumi sebagai suatu lingkungan fisik yang meliputi tanah beserta segenap faktor yang mempengaruhi penggunaanya seperti iklim, relief, aspek geologi, dan hidrologi yang terbentuk secara alami maupun akibat pengaruh manusia. $^{13}$

Alih fungsi lahan merupakan kegiatan perubahan penggunaan tanah dari suatu kegiatan yang menjadi kegiatan lainnya. Alih

${ }^{13}$ I Gusti Ngurah Alit Saputra dan Ni Wayan Hatika Sucoi,2019 Cegah Alih Fungsi Lahan Pertanian Melalui Awig-Awig ( Studi di Desa Pakraman Sumampan, Gianyar), Jurnal Widya Wertta, Volume 2, Nomor 2, Tahun 2019, p-ISSN: 0852-7776, h. 246-247. 
fungsi lahan muncul sebagai akibat pembangunan dan peningkatan jumlah penduduk. Pertambahan penduduk dan peningkatan kebutuhan lahan untuk kegiatan pembangunan telah merubah struktur pemilikan dan penggunaan lahan secara terus menerus ${ }^{14}$. Perkembangan struktur industri yang cukup pesat berakibat terkonversinya lahan pertanian secara besar-besaran. Selain untuk memenuhi kebutuhan industri, alih fungsi lahan juga terjadi secara cepat untuk memnuhi kebutuhan perumahan yang jumlahnya jauh lebih besar. Alih fungsi lahan merupakan fenomena yang tidak dapat dihindarkan dari pembangunan $^{15}$.

Terkait dengan keberadaan Hukum adat dalam hal memiliki peranan dalam melindungi kawasannya dari alih fungsi lahan, maka dapat dilihat terlebih dahulu dari kewenangan yang diberikan oleh negara kepada masyarakat adat untuk mengelola wilayahnya sendiri yaitu dapat dilihat dalam Pasal 18D ayat 2 Undang-Undang Dasar 1945

$$
\begin{aligned}
& { }^{14} \text { Ibid } \\
& { }^{15} \text { Ibid }
\end{aligned}
$$

menyatakan : Negara mengakui dan menghormati kesatuan-kesatuan masyarakat hukum adat beserta hakhak tradisionalnya sepanjang masih hidup dan sesuai dengan perkembangan masyarakat dan prinsip negara Kesatuan Republik Indonesia, yang diatur dalam Undang-Undang ${ }^{16}$. maka lebih lanjut dapat dilihat berdasarkan Pasal 18D Undang-Undang Dasar 1945 terdapat beberapa unsur yaitu: (1) bahwa negara melalui Konstitusi dan peraturan Perundang-undangan turunan dari konstitusi di Negara Kesatuan Republik Indonesia memberikan suatu jaminan kepada kesatuan-kesatuan masyarakat hukum adat beserta hak-hak tradisional yang dimiliki oleh kesatuan-kesatuan hukum adat tersebut; (2) bahwa jaminan yang diberikan oleh negara melalui Konstitusi dan peraturan Perundangundangan turunan dari konstitusi di Negara Kesatuan Republik Indonesia sepanjang kesatuan-kesatuan masyarakat hukum adat tersebut masih hidup; (3) Jaminan yang diberikan kepada negara Konstitusi

${ }^{16}$ Ibid, h. 30 
dan peraturan Perundang-undangan turunan dari konstitusi di Negara Kesatuan Republik Indonesia diberikan apabila kesatuan-kesatuan masyarakat hukum adat tersebut sesuai perkembangan masyarakat; (4) bahwa jaminan yang diberikan oleh negara melalui Konstitusi dan peraturan Perundang-undangan turunan dari konstitusi di Negara Kesatuan Republik Indonesia diberikan selama kesatuan-kesatuan masyarakat hukum adat tidak bertentangan dengan prinsip-prinsip yang ada di dalam Negara Kesatuan Republik Indonesia.

Salah satu kewenangan dari masyarakat hukum adat yang diberikan oleh negara adalah membuat hukum adat di wilayahnya sendiri untuk mengatur rumah tangganya sendiri. Hukum Adat adalah hukum yang berlaku dan berkembang dalam lingkungan masyarakat di suatu daerah. ${ }^{17}$ Ada beberapa pengertian mengenai Hukum Adat. Menurut B. Ter Haar Bzn, hukum adat adalah keseluruhan

\footnotetext{
17 Marco Manarisip, Eksistensi Pidana Adat Dalam Hukum Nasional, Jurnal Lex Crimen, Volume 1, Nomor 4, Desember 2012, ISSN : 2301- 8569, h. 25.
}

aturan yang menjelma dari keputusan-keputusan para fungsionaris hukum (dalam arti luas) yang memiliki kewibawaan serta pengaruh dan yang dalam pelaksanaannya berlaku serta merta dan ditaati dengan sepenuh hati. ${ }^{18}$ J.H.P. Bellefroid, hukum adat adalah peraturan hidup yang meskipun tidak diundangkan oleh penguasa tapi dihormati dan ditaati oleh rakyat dengan keyakinan bahwa peraturanperaturan tersebut berlaku sebagai hukum. ${ }^{19}$ Dan menurut Hardjito Notopuro, hukum adat adalah hukum tak tertulis, hukum kebiasaan dengan ciri khas yang merupakan pedoman kehidupan rakyat dalam menyelenggarakan tata keadilan dan kesejahteraan masyarakat dan bersifat kekeluargaan. ${ }^{20}$

Keberadaan hukum Desa Adat Begawan baik berupa Awig-awig, Pararem maupun Dresta menjadi acuan dasar masyarakat Desa adat Begawan dalam kehidupan seharihari, apalagi di dalam awig-awig

${ }^{18}$ C. Dewi Wulansari, 2016, , Hukum Adat indonesia Suatu penghantar, Cet-4 PT. Refika Aditama, Bandung, h. 4.

${ }^{19}$ Ibid.

${ }^{20}$ Ibid. 
Desa Adat Begawan terdapat tidak mengganggu keharmonisan filosofis Tri Hita Karana yang salah warga Desa Adat Begawan yang satu pedomannya berisikan sesuai dengan Tri Hita Karana. Palemahan yang memiliki arti hubungan yang harmonis antara masyarakat Desa Adat Begawan dengan lingkungannya. Adanya hukum Desa Adat Begawan dapat memberikan kewenangan kepada masyarakat hukum adat di wilayah Desa Adat Begawan untuk menjaga kelestarian dari wilayah yang dikelola oleh mereka, bahkan kewenangan memberikan denda bagi masyarakat yang melanggar aturan hukum adat tersebut yang terkait dengan pelestarian alam dari pencegahan alih fungsi lahan di kawasan aliran sungai Ayung.

Di dalam awig-awig Desa Adat Begawan mengenai pembangunan, yaitu terdapat pada Pawos 30 yang mengisyaratkan kepada warga yang hendak membangun harus memberitahu atau memberikan informasi kepada Prajuru/ Dulu, supaya dalam pembangunannya tidak terjadi masalah di kemudian hari. Hal ini juga berfungsi untuk memantau bangunan yang dibangun di kawasan Desa Adat Begawan agar Seperti halnya, dikarenakan letak dari Desa Adat Begawan yang memiliki wilayah tebing yang curamdan kawasan alira sungai di sebelah barat wilayah desa, maka bagi masyarakat lokal maupun masyarakat pendatang yang hendak membangun suatu bangunan, baik berupa rumah, restora maupun hotel ataupun bagunan yang diperuntukkan hal-hal lainnya di area tersebut di wajibkan untuk memberikan informasi kepada kepala adat Desa Adat Begawan sebagai filter agar tidak mengganggu kehidupan masyarakat dan lingkungan alam di wilayah Desa Adat Begawan.

\section{PENUTUP}

\section{Kesimpulan}

Peranan hukum adat yang dimiliki oleh desa adat Begawan baik berupa Awig-awig, Pararem mapun kebiasaan dalam bentuk dresta dalam melidungi kawasan aliran sungai ayung adalah untuk memberikan legalitas atau payung hukum bagi masyarakat desa adat begawan dalam melindungi dan 
melestarikan kawasan aliran sungai ayung agar sesuai dengan filosofis Tri Hita Karana

\section{DAFTAR PUSTAKA}

BUKU:

Wulansari, C. Dewi, 2016, Hukum Adat indonesia Suatu penghantar, Cet 4, PT. Refika Aditama, Bandung.

\section{PERATURAN PERUNDANG- UNDANGAN:}

Undang-Undang Dasar Negara Republik Indonesia Tahun 1945.

Undang-Undang Nomor 41 Tahun 2009 Tentang Perlindungan Lahan Pertanian Dan Pangan Berkelanjutan, Lembaran Negara Republik Indonesia Tahun 2009 Nomor 149, Tambahan Lembaran Negara Republik Indonesia Nomor 5068.

Peraturan Daerah Provinsi Bali Nomor 4 Tahun 2019 tentang Desa Adat di Bali, Lembaran Daerah Provinsi Bali Tahun 2019 Nomor 4, Tambahan Lembaran Daerah Provinsi Bali Nomor 4.

Awig-Awig Desa Adat Begawan, Desa Melinggih Kelod, Kecamatan Payangan, Kabupaten Gianyar.

\section{JURNAL:}

Saputra, I Gusti Ngurah Alit dan Ni Wayan Hatika Sucoi, 2019,
Cegah Alih Fungsi Lahan Pertanian Melalui Awig-Awig ( Studi di Desa Pakraman Sumampan, Gianyar), Jurnal Widya Wertta, Volume 2, Nomor 2, Tahun 2019.

Manarisip, Marco, Eksistensi Pidana Adat Dalam Hukum Nasional, Jurnal Lex Crimen, Volume 1, Nomor 4, Desember 2012.

Dewi, Ni Made Lidia Lestari Karlina, 2019, Peran Desa Pakraman Dalam Pembentukan Pararem Terkait Penyelesaian Konflik Alih Fungsi Lahan (Studi Kasus Di Desa Pakraman Tunjuk, Kabupaten Tabanan), Jurnal Magister Hukum Udayana, Volume 5, Nomor 3, September 2016.

\section{INTERNET:}

Como Shambhala estate, 2019, Como Shambhala estate, https://www.comohotels.com /en/comoshambhalaestate, diakses pada 20 November 2019.

Ayung Resort Ubud, 2019, Ayung Resort Ubud https://www.ayungresortubud .com/en-gb, diakses pada 20 November 2019.

Rijasa Agung - Bali Ubud Luxury Hotel Resort Villa, 2019, Rijasa Agung - Bali Ubud Luxury Hotel Resort Villa, ijasa.com, diakses pada 20 November 2019. 
Hikersbay,Villa Gana Begawan, http://hikersbay.com/asia/ind onesia/hotel/id/villa-ganabegawan.html?lang=en, diakses pada 20 November 2019.

Radar Bali, 2018, Alih Fungsi Lahan Empat Kecamatan di Tabanan Masif, Ini Pemicunya, https://radarbali.jawapos.com/r ead/2018/04/16/65481/alihfungsi-lahan-empatkecamatan-di-tabanan-masifini-pemicunya, diakses pada 21 November 2019.

Tribun Bali.com.2017, Sungai Ayung Badung Tercemar, eh longsor bikin petani tidak bisa menanam, https://bali.tribunnews.com/20 17/03/04/sungai-ayungbadung-tercemar-eh-longsorbikin-petani-tak-bisamenanam, diakses pada 21 November 2019. 